\title{
Community-level consequences of species interactions in an annual plant community
}

\author{
Rajaniemi, Tara K. ${ }^{1 *}$; Turkington, Roy ${ }^{2,3} \&$ Goldberg, Deborah ${ }^{4,5}$ \\ ${ }^{1}$ Biology Department, University of Massachusetts Dartmouth, 285 Old Westport Road, North Dartmouth, \\ MA 02747, USA; ${ }^{2}$ Department of Botany, and Biodiversity Research Center, University of British Columbia, Vancouver, \\ Canada BCV6T 1Z4; ${ }^{3}$ E-mail royt@interchange.ubc.ca; ${ }^{4}$ Department of Ecology and Evolutionary Biology, University \\ of Michigan, Ann Arbor, MI 48109-1048,USA; ${ }^{5}$ E-mail degold@umich.edu \\ *Corresponding author; E-mail trajaniemi@umassd.edu
}

\begin{abstract}
Question: How does the intensity of species interactions affect species and functional group composition of an annual plant community?
\end{abstract}

Location: Sede Boqer, Negev Desert, Israel.

\begin{abstract}
Methods: The potential for competitive interactions in two annual plant communities (desert and coastal) from semistabilized sand dunes was manipulated by varying seed bank density and therefore the number of potentially interacting individuals. Communities were exposed to three different irrigation regimes, mimicking precipitation at the desert site, the coastal site, and an intermediate precipitation level. Plots were maintained for 3 years, and percentage cover of each species in the plots was recorded at the end of each growing season. We used redundancy analysis to test for effects of initial density, irrigation, and year on the species and functional group composition of the communities.
\end{abstract}

Results: Initial density had significant effects on species composition, and these effects remained significant over 3 years, even as total community percentage cover became more similar among treatments over time. Density effects did not depend on resource availability (irrigation level). Functional group identity or individual plant size did not predict which species would be good competitors, and a species' competitive ability did not predict its abundance in the field.

Conclusions: Species interactions strongly affect community composition, and those effects carry over into subsequent years such that competition does not lead to convergence in community structure over time. However, the particular changes in composition observed were not predictable by some of the traits that have been found important in individual-level experiments. We speculate that the outcome of competition in diverse communities will depend on multiple traits, in contrast to the outcome of individual-level pairwise experiments. We also speculate that the shift in composition with density could mean that local variation in density may contribute to maintenance of diversity in this system.

Keywords: Community density; Competition; Convergence; Desert annuals; Functional group composition; Species composition.

Nomenclature: Feinbrun-Dothan \& Danin 1991

\section{Introduction}

The importance of competition has long been a central question in plant community ecology. Most of the theory explaining patterns in community structure, including species composition, dominance, and diversity, assigns competition a key role (Newman 1973; Grime 1979; Tilman 1988; Keddy 1990, 2001; Taylor et al. 1990; Chase \& Leibold 2003). Despite the fact that this theory aims to explain community-level patterns, most of the experimental work directly manipulating the intensity of competition has investigated its individual-level consequences (Goldberg \& Barton 1992; Goldberg et al. 1999; Reynolds \& Rajaniemi 2007).

Such individual-level data are inadequate for predicting changes in the relative abundances of species within a community. While survival, growth, and reproduction may all reflect aspects of individual fitness, it is often unknown which of these, alone or in combination, have the greatest influence on population dynamics (McPeek \& Peckarsky 1998; Goldberg et al. 1999). Furthermore, even with an appropriate choice of response variable, 
individual-level effects may not scale up to the community level (Rajaniemi \& Goldberg 2000; Zamfir \& Goldberg 2000) because community dynamic effects depend on how each species is affected by competition relative to how all other species in the community are affected (Goldberg 1994).

The lack of data on community-level effects of competition means that we cannot test general hypotheses about the importance of species interactions for community structure, such as whether the importance of competition changes along productivity gradients or with disturbance intensity (Grime 1973; Huston 1979; Oksanen et al. 1981; Tilman 1982, 1988; Bertness \& Callaway 1994; Michalet et al. 2006). We are also limited in our ability to test hypotheses relating plant traits, competitive ability, and dominance within and across environments (e.g., Grime 1979; Chapin 1980; Tilman 1988; Aerts 1999; Craine 2005).

To assess effects of species interactions on the entire community, interactions among all species must be manipulated simultaneously so that community structure with and without interactions can be compared. Two methods have been proposed to determine the "null community" without or with minimal interactions. Each species may be grown in monoculture, with the combined monocultures representing the community free of species interactions (Goldberg 1994; Zamfir \& Goldberg 2000; Rajaniemi et al. 2003; Lenssen et al. 2004). This approach can investigate effects of interspecific interactions while maintaining intraspecific interactions. Alternatively, the community may be grown at a low enough total density to preclude both inter- and intraspecific interactions among individuals (Goldberg et al. 1995; Goldberg \& Estabrook 1998; Rajaniemi \& Goldberg 2000). If initial relative abundances and diversity (adjusted for density) are kept similar between low- and high-density communities, differences that develop over time can be attributed to differences in intensity of species interactions.

In this study, we experimentally manipulated initial densities of entire, diverse communities of annual plants to examine community-level impacts of interactions, and simultaneously manipulated irrigation levels, to determine whether the impact of interactions was dependent on resource availability. Shilo-Volin et al. (2005) used this approach to demonstrate that species interactions regulate total community abundance (plant density and cover), and that regulation is strongest with low irrigation. In this study, we asked whether similar regulation of species composition occurs. We tracked percentage cover of individual species over 3 years, to explore the effects of species interactions and resource levels on community composition. Specifically, we tested the following predictions:

1. Community composition will shift in response to initial differences in the potential for species interactions due to planting density.

2. The community composition response to initial density will be stronger under low irrigation, consistent with our previous studies in this system that suggest that the effects of competition on individual performance and on total community abundance are greatest at low resource levels (Goldberg et al. 2001; Shilo-Volin et al. 2005).

3. Total community abundance, and community composition, will both become more similar among density treatments over time.

4. Grasses, species with large individual biomass, and species that are most abundant in the field will be the strongest competitors, performing best at high initial densities. Previous studies have shown that grasses are superior individual-level competitors to dicots in this system when response is measured as emergence or survival but not growth (Goldberg et al. 2001). However, these responses may or may not scale up to relative abundance in the community. In general, large size is expected to contribute to a strong competitive effect (Goldberg \& Landa 1991), and good competitive ability should lead to dominance in natural communities (Tilman 1982; Howard 2001).

\section{Methods}

\section{System and basic approach}

The system consisted of annual plants occurring at two semi-stabilized sand dune sites in Israel - one desert and one coastal community (source sites). Mean annual precipitation [MAP] (30-year average) is $110 \mathrm{~mm}$ at the desert site (Holot Mashabim, $31^{\circ} 00^{\prime} \mathrm{N} 34^{\circ} 44^{\prime} \mathrm{E}$ ), and $550 \mathrm{~mm}$ at the Mediterranean coastal site (Caesarea $32^{\circ} 30^{\prime} \mathrm{N} 34^{\circ} 55^{\prime} \mathrm{E}$ ). Our basic approach was to grow both communities in a common garden, manipulating irrigation to mimic the rainfall regimes of both source sites and an intermediate regime, and manipulating initial community density to vary the potential for species interactions. The experimental system and general methodology is described in detail by Goldberg et al. (2001) and Shilo-Volin et al. (2005). 


\section{The experimental garden}

The annual plant communities from the two source sites were both grown in a common garden constructed at the Blaustein Institute for Desert Research at Sede Boqer $\left(30^{\circ} 48^{\prime} \mathrm{N} 34^{\circ} 48^{\prime} \mathrm{E}\right.$; MAP $99 \mathrm{~mm}$ ), about $25 \mathrm{~km}$ southeast of the desert source site of Holot Mashabim. The garden comprised multiple trenches. To construct a trench, the existing loessial soil was removed from a $2 \mathrm{~m} \times 10 \mathrm{~m}$ area to a depth of $1 \mathrm{~m}$; corrugated plastic liners were placed in the excavated area to separate the trench from the surrounding soil and to divide the trench itself into 16 experimental plots, eight large $(1 \mathrm{~m} \times 1 \mathrm{~m})$ and eight small $(0.50 \mathrm{~m} \times 0.50 \mathrm{~m})$. The plots were filled with sterile sand collected from at least $10 \mathrm{~m}$ below the surface from a commercial quarry located in the same dune system as the Holot Mashabim source site. For this experiment, we used four large and two small plots in each of 12 trenches (see Experimental design, below).

\section{Density treatments: seed bank collection and preparation}

At each source site, we collected the seed bank from 60 random locations by removing the top $2 \mathrm{~cm}$ of soil. The samples from within each source site were combined and then passed through a series of sieves to eliminate the sand. The smallest fraction $(<500 \mu \mathrm{m})$ contained almost no seeds and was not used. The rest of the seed bank was combined for each source and thoroughly mixed to use as the concentrated seed bank.

Three initial planting densities were established by sowing different amounts of this homogenized, concentrated seed bank on the surface of the plots: $1 / 16$ of average natural $(1 / 16 \times)$, average natural field density $(1 \times)$, and four times average natural density $(4 \times)$. Average natural density was achieved by adding to the plot the mean mass of seed bank collected from the equivalent area at the source site; this density therefore represents an average of the seed bank densities in the 60 plots from which seed bank was collected. This approach allowed us to change the seed density while keeping the initial relative abundances of species constant, without having to count or identify individual seeds.

\section{Irrigation treatments}

Three irrigation treatments were imposed that mimicked aspects of the precipitation regimes of the two source sites, and an intermediate regime. Long- term rainfall records indicate that, on average, the desert and coastal sites receive, respectively, 1.1- and 5.8-times the annual precipitation of the garden site at Sede Boqer. After each naturally occurring rainfall event at Sede Boqer, water was supplied to the irrigation treatments to maintain these proportional differences, with the intermediate treatment receiving the midpoint of these extremes (3.45-times precipitation at Sede Boqer). If no rain fell at the garden site for a period of 2 weeks, each of the plots was irrigated with the equivalent of $1 / 12$ of the mean annual precipitation for the desert site (in the low treatment), coastal site (in the high treatment), or the midpoint (in the intermediate treatment).

\section{Experimental design}

The basic design was a factorial of three initial community densities $(1 / 16 \times, 1 \times$ and $4 \times$ average natural density) $\times$ three irrigation treatments (low, intermediate, and high) $\times$ two source communities (desert and coastal), all replicated in four blocks. Because irrigation treatments could only be assigned to entire trenches, we used a nested block design, with three trenches in each block. One trench of each block was assigned randomly to an irrigation regime and the combinations of source and density treatments were then assigned randomly within each trench. Thus, source and density are nested within irrigation treatments. The higher seed bank densities $(4 \times$ and $1 \times$ natural) were planted into small $(0.5 \mathrm{~m} \times 0.5 \mathrm{~m})$ plots, and the lowest density $(1 / 16 \times)$ was planted in the larger $\left(1 \mathrm{~m}^{2}\right)$ plots. In other experiments in this experimental garden (Rajaniemi et al. unpublished data) in which natural densities were planted into both large and small plots, plot size did not affect biomass density, and the total number of plants was similar in large $1 / 16 \times$ plots and small $1 \times$ plots. Thus, using larger plots for the lowest density allows for more valid comparisons of species relative abundances, because rare species should not be lost from low density plots due to low sample size, and is not expected to confound analyses of plant biomass.

In summary, within each block of three trenches, the six combinations of source and irrigation treatment were each replicated once for each of the three density treatments, for a total of 18 plots in each of the four blocks, and a grand total of 72 plots.

\section{Planting, monitoring, and maintenance of experimental communities}

The plots were planted in November 1993 by spreading the appropriate amount of seed bank 
uniformly across the surface of the sand of each plot. The seed bank was then covered with $1 \mathrm{~cm}$ of sterile sand and lightly watered with an equivalent of $5 \mathrm{~mm}$ of rainfall to prevent loss of the seed bank by wind. Each plot had a 10-cm buffer zone that we did not monitor. Therefore, effective plot sizes were $80 \mathrm{~cm} \times 80 \mathrm{~cm}$ and $30 \mathrm{~cm} \times 30 \mathrm{~cm}$ for large and small plots, respectively.

In May 1994 and 1995, after the end of the growing season, the plots were covered with mesh screens to prevent dispersal and seed predation during the summer. In addition, throughout the experiment, ant activity was largely eliminated by local applications of insecticide. Mesh screens were removed in the early fall before initiation of the rainy season. Major branches of the senesced plants were clipped, chopped, and returned to the plots to ensure that seeds remaining on the plants were part of the potentially emerging seed bank. The litter layer was then covered with $1 \mathrm{~cm}$ of fresh sand and watered as after the initial planting.

Percentage cover estimates were made in late April 1994, 1995, and 1996 after cessation of natural rainfall and as most species were just beginning to dry after ripening seeds. For each of 25 points in small plots, and 49 points in large plots, the presence or absence of each species was recorded. These data provide a measure of relative abundance of species, but cannot be combined to give total cover of the community. As an indicator of total abundance, in April 1996 aboveground biomass from a subset of 27 of the 72 plots was harvested, dried, and weighed.

\section{Statistical analyses}

The harvest biomass data were used to test whether different initial planting densities converged in total abundance by the end of the third growing season. Source community did not affect total plot biomass (one-way ANOVA, $F_{1,25}<0.001$, $P=0.999$ ), so sources were combined to provide a sufficient sample size to test for the effects of planting density and irrigation in a nested ANOVA (with irrigation treatments nested within trenches). Multiple comparisons were done using the Sidak method.

We used a multivariate analysis to test for effects of treatments on functional group composition and species composition of the community. Species were assigned to one of four functional groups: annual grasses, annual legumes, annual non-legume dicots, and perennials (hereafter, grasses, legumes, dicots, and perennials). Perennials were a minor component of both communities and included a total of two dicot species and one grass species.

Separate analyses were conducted for species and for functional groups, for each of the two source communities. Percentage cover of each species or functional group was square-root transformed to reduce the influence of dominant species relative to rarer ones, and values were standardized by sample. First, principal components analysis (PCA) was conducted to visualize community responses to experimental treatments. Then, we used redundancy analysis (RDA) with a repeated measures design to test for main effects and interactions of density, irrigation, and year on functional group composition and on species composition. Significance was determined by permutation tests. Trench was not included in these analyses due to software limitations. These analyses were conducted using CANOCO v 4.5 (Microcomputer Software, Ithaca, NY, US) and ordination diagrams were drawn using CanoDraw 4 (Microcomputer Software).

Linear regression was used to test whether species' competitive ability was related to their potential individual size or to their relative abundance in the field. We assessed community-level competitive ability by responses to planting density: species that increased in relative abundance at high relative to low density did relatively better with more intense competition and were considered better competitors. We emphasize that increases in relative abundance at high density do NOT imply that individual fitness components were facilitated at high density; we know from earlier studies that high planting density reduced both emergence and growth of individuals in this system (Goldberg et al. 2001). Instead, it means that individual fitness of a good community-level competitor was reduced less by competition at high densities than fitness of poorer competitors. As an index of how relative abundance changed with density, competitive ability was quantified by species score on the PCA axis associated with planting density (axis 2 for the desert community; axis 1 for the coastal community).

The two species characteristics we tested for relationships with competitive ability, maximum individual size and mean relative abundance in the field, were measured independently of this study. The maximum dry mass of an individual from each species was derived from an experiment similar to this one, in which the same communities were grown at the same irrigation levels for only a single growing season, but at a broader range of starting densities (see Goldberg et al. 2001 for details of experimental design). For each plot, individual biomass of each 
species was calculated as the total shoot biomass for that species in the plot, divided by the number of shoots of that species in the plot. For each species, the maximum value of individual biomass was selected from all plots in a given irrigation treatment. Here, we report results for maximum individual biomass under high irrigation; results were similar for intermediate and low irrigation. Field relative abundance was calculated by averaging relative biomass of each species over 5 years in field surveys from the seed source sites (see Rajaniemi et al. 2006 for description of field sampling procedures). Values of individual plant biomass and relative abundance were ln-transformed to improve homogeneity of variance.

\section{Results}

\section{Total community abundance}

The biomass of plots planted at different initial densities had not entirely converged by the end of the third year, as indicated by a significant effect of planting density on final biomass $\left(F_{2,15}=5.722\right.$, $P=0.014$; Fig. 1), with $1 / 16 \times$ plots having lower final biomass than $1 \times$ and $4 \times$ plots $(P=0.006$ and $P=0.001$, respectively). There was no significant effect of irrigation on final biomass $\left(F_{2,3}=1.579\right.$, $P=0.360$ ), and a marginally significant irrigation $\times$ density interaction $\left(F_{4,15}=2.926, P=0.057\right)$. Convergence tended to be stronger under low irrigation (Fig. 1).

\section{Species composition}

For the desert community, the first and second PCA axes explained $19.8 \%$ and $12.6 \%$ of variation in species composition, respectively. Axis one was associated with a shift in composition between the first year of the experiment and the second and third

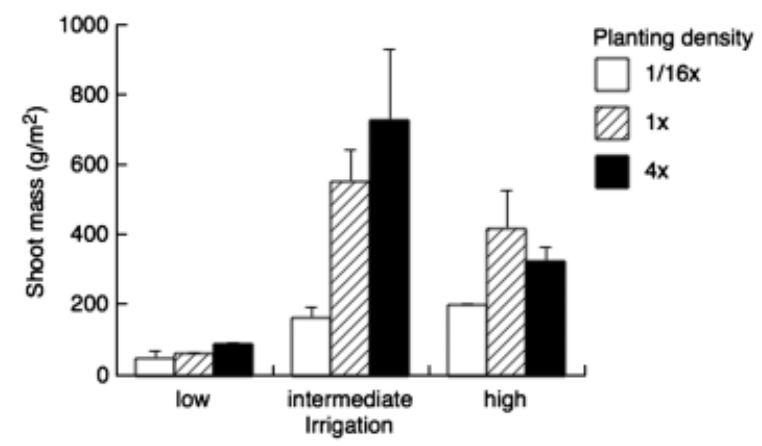

Fig. 1. Total shoot biomass ( $\pm 1 \mathrm{SE})$ at harvest in a subset of plots. years. A suite of common species, including grasses, dicots, and legumes, determined scores on the first axis (Fig. 2). Axis two separated plots with low planting density from those with natural and high density. To a lesser extent, this axis also separated the irrigation treatments. A high value on this axis reflected high relative abundance of the grass Aegilops sharonensis, while low values reflected high relative abundance of the grass Aegilops kotschyi and the dicots Erodium laciniatum and Rumex pictus (Fig. 2).

In the coastal community, the first and second PCA axes explained $18.1 \%$ and $13.9 \%$ of variation in species composition, respectively. In this community, axis one differentiated low-density plots from natural and high-density plots. Axis one scores reflected a shift from high relative abundance of the grass $A$. sharonensis to high relative abundance of the grass Cutandia philistaea (Fig. 2). Axis two scores separated year 1 from years 2 and 3 , with a small effect of irrigation treatment. Plots with high scores on axis two were dominated by the grasses A. kotschyi and Brachypodium distachyon and the dicot E. laciniatum, while plots with low scores were dominated by the grass Bromus rigidus and the dicot Rumex bucephalophorus (Fig. 2).

In both of the communities, year, density, and irrigation all had significant effects on species composition in RDA (Table 1). The year $\times$ density and year $\times$ irrigation $\times$ density interactions were not significant, indicating that there was no consistent convergence (or divergence) of species composition over time among plots planted at different initial densities (Table 1).

\section{Functional group composition}

In the desert community, the first and second PCA axes explained $67.8 \%$ and $26.4 \%$, respectively, of variation in functional group composition. Axis one separated year 1 of the experiment from the second and third years; this axis also separated the natural density plots from those planted with high and low density. The year effect was significant, but the density effect was not (Table 2). This axis strongly separated plots dominated by dicots early in the experiment from those dominated by grasses later in the experiment (Fig. 3). Axis two separated low-irrigation plots from intermediate and high irrigation (significant irrigation effect, Table 2), and was associated with increasing abundance of legumes at higher irrigation (Fig. 3). The year $\times$ density interaction did not affect functional group composition in the desert community (Table 

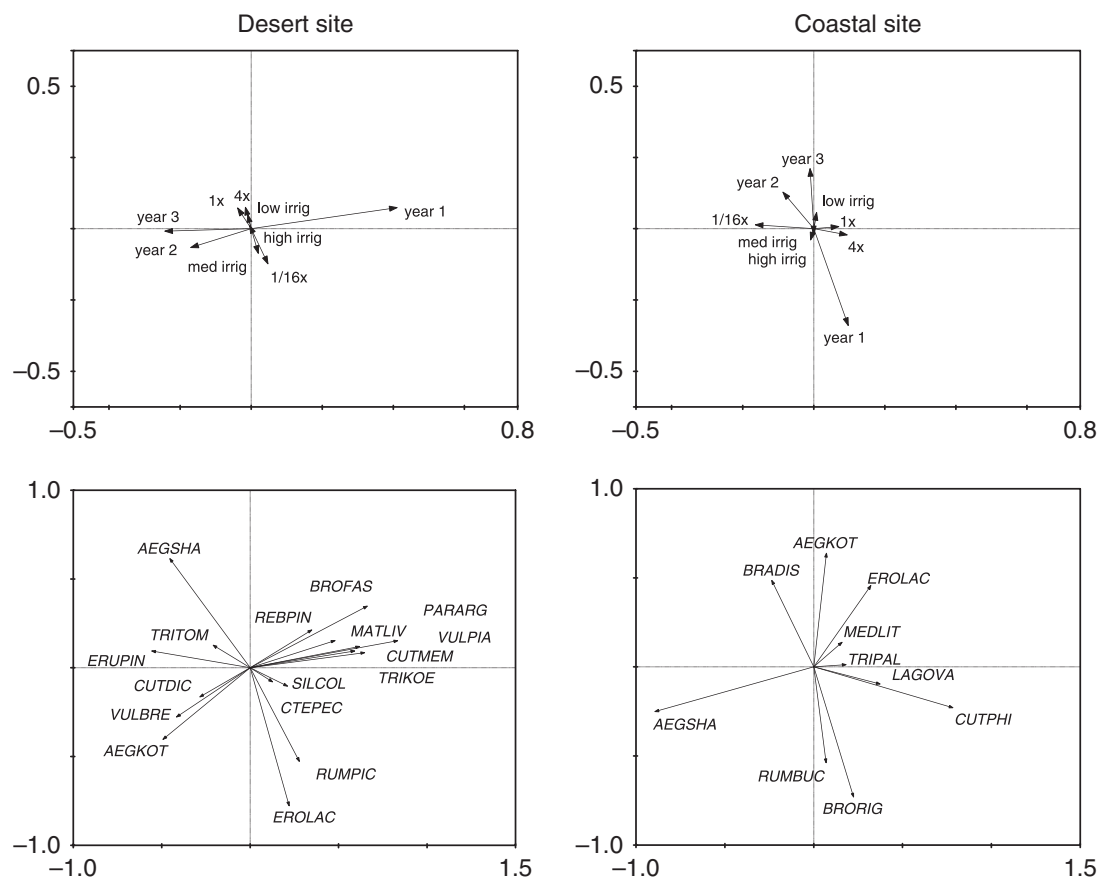

Fig. 2. Ordination diagrams for PCA on species composition, showing environmental variables (experimental treatments) and species for the two source communities. PCA was carried out separately for the two communities. Species occurring in at least 20 plots are shown. Species codes for the desert site: Grasses - AEGKOT, Aegilops kotschyi; AEGSHA, Aegilops sharonensis; BROFAS, Bromus fasciculatus; CTEPEC, Ctenopsis pectinella; CUTDIC, Cutandia dichotoma; CUTMEM, Cutandia memphitica; TRIKOE, Trisetaria koelerioides; VULBRE, Vulpia brevis; VULPIA, Vulpia sp. Dicots - EROLAC, Erodium laciniatum; ERUPIN, Erucaria pinnata; MATLIV, Matthiola livida; PARARG, Paronychia argentea; REBPIN, Reboudia pinnata; RUMPIC, Rumex pictus; SILCOL, Silene colorata. Legume - TRITOM, Trifolium tomentosum. Species codes for the coastal site: Grasses - AEGKOT, Aegilops kotschyi; AEGSHA, Aegilops sharonensis; BRADIS, Brachypodium distachyon; BRORIG, Bromus rigidus; CUTPHI, Cutandia philistaea; LAGOVA, Lagurus ovatus. Dicots - EROLAC, Erodium laciniatum; RUMBUC, Rumex bucephalophorus. Legumes - MEDLIT, Medicago littoralis; TRIPAL, Trifolium palaestina.

Table 1. Effects of year, irrigation level, and planting density on species composition. Significance of all canonical axes in redundancy analysis is shown. Values in bold are significant $(P<0.05)$.

\begin{tabular}{lccccc}
\hline & \multicolumn{2}{l}{ Desert site } & & \multicolumn{2}{l}{ Coastal site } \\
\cline { 2 - 3 } \cline { 5 - 6 } & $F$-value & $P$-value & & $F$-value & $P$-value \\
\hline Year & 12.745 & $\mathbf{0 . 0 0 2}$ & & 8.184 & $\mathbf{0 . 0 0 2}$ \\
Irrigation & 3.900 & $\mathbf{0 . 0 0 2}$ & & 3.121 & $\mathbf{0 . 0 0 2}$ \\
Density & 2.265 & $\mathbf{0 . 0 3 4}$ & & 3.141 & $\mathbf{0 . 0 0 2}$ \\
Year:Irrig & 1.773 & $\mathbf{0 . 0 0 2}$ & & 2.437 & $\mathbf{0 . 0 0 2}$ \\
Year:Density & 1.002 & 0.158 & & 0.900 & 0.442 \\
Irrig:Density & 1.467 & 0.306 & & 0.939 & 0.860 \\
Year:Irrig:Density & 1.120 & 0.076 & & 1.119 & 0.086 \\
\hline
\end{tabular}

2), indicating no convergence of functional group composition over time.

For the coastal community, the first and second PCA axes explained $50.6 \%$ and $44.5 \%$, respectively, of variation in functional group composition. Axis one separated years 1 and 2 of the experiment from year 3 (significant year effect, Table 2), and reflected
Table 2. Effects of year, irrigation level, and planting density on functional group composition. Significance of all canonical axes in redundancy analysis is shown. Values in bold are significant $(P<0.05)$.

\begin{tabular}{lccccc}
\hline & \multicolumn{2}{l}{ Desert site } & & \multicolumn{2}{l}{ Coastal site } \\
\cline { 2 - 3 } & $F$-value & $P$-value & & $F$-value & $P$-value \\
\hline Year & 5.385 & $\mathbf{0 . 0 0 4}$ & & 4.339 & $\mathbf{0 . 0 0 2}$ \\
Irrigation & 4.809 & $\mathbf{0 . 0 0 2}$ & & 3.310 & $\mathbf{0 . 0 0 6}$ \\
Density & 0.975 & 0.438 & & 2.076 & 0.078 \\
Year:Irrig & 2.548 & $\mathbf{0 . 0 2 0}$ & & 4.004 & $\mathbf{0 . 0 0 4}$ \\
Year:Density & 0.624 & 0.720 & & 1.245 & 0.266 \\
Irrig:Density & 0.454 & 0.890 & & 1.419 & 0.166 \\
Year:Irrig:Density & 0.876 & 0.648 & & 1.528 & $\mathbf{0 . 0 2 8}$ \\
\hline
\end{tabular}

a shift from dicots to grasses over time (Fig. 3). Axis two differentiated plots with high irrigation from plots with low irrigation (significant irrigation effect, Table 2), and low-planting density from natural and high-planting density (not significant, Table 2). This axis reflected an increase in abundance of legumes at higher irrigation and higher initial density 

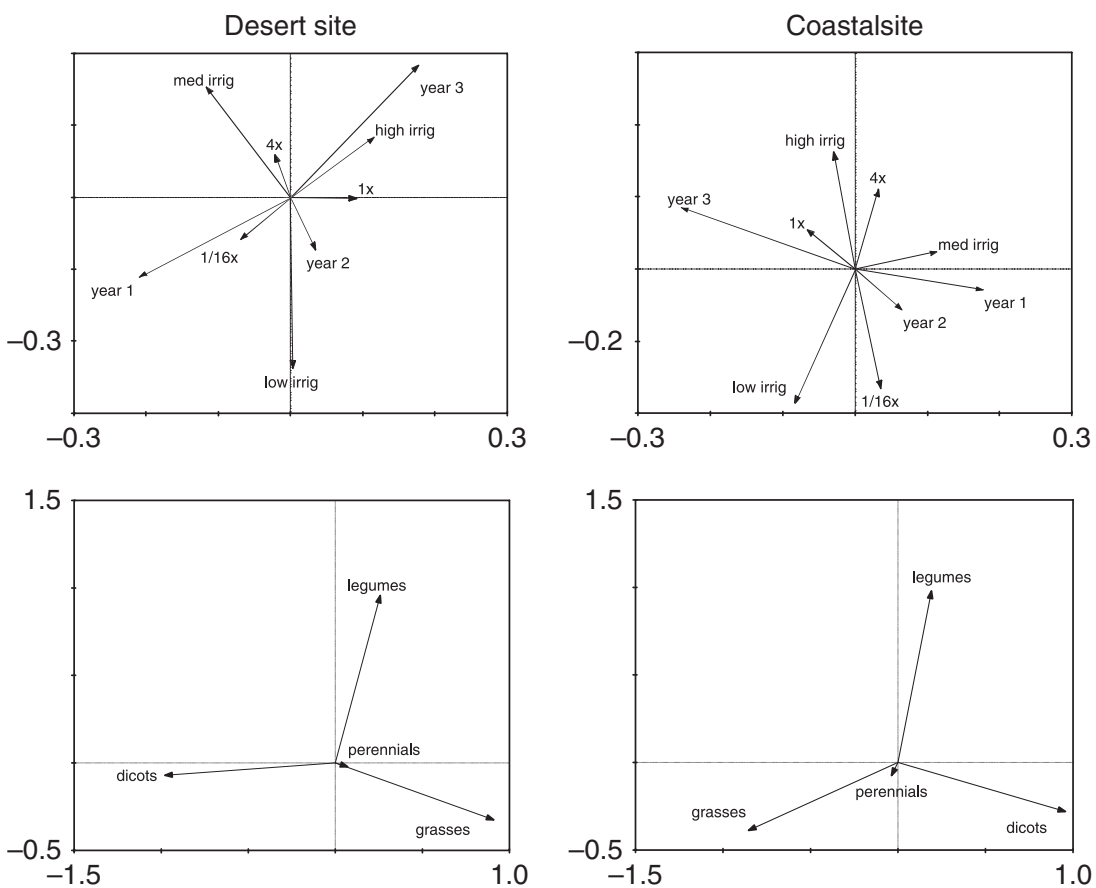

Fig. 3. Ordination diagrams for PCA on functional group composition, showing environmental variables (experimental treatments) and functional groups for the two source communities. PCA was carried out separately for the two communities.

(Fig. 3). In the coastal community, functional group composition was significantly affected by a year $\times$ irrigation $\times$ density interaction (Table 2). Communities with different starting densities converged in functional group composition only in the low irrigation treatment (not shown).

\section{Competitive ability of species}

For the desert community, we defined competitive ability of a species as its loading on PCA axis two; higher values indicate greater increase in relative abundance under higher planting densities with more intense species interactions $(1 \times$ and $4 \times$ planting densities) (Fig. 2). Contrary to our predictions, these scores were not related to the maximum biomass of individuals of the species, as determined in a separate experiment $\left(r^{2}=0.019, P=0.501\right)$, or to average relative abundance of the species in the field $\left(r^{2}=0.017, P=0.415\right)$.

For the coastal community, high scores on the first PCA axis reflected good competitive ability (high relative abundance under $1 \times$ and $4 \times$ planting densities; Fig. 2). Again, these scores were not related to the maximum biomass of individuals of the species as determined in a separate experiment $\left(r^{2}=0.003, P=0.819\right)$, or to average relative abundance of the species in the field $\left(r^{2}=0.011\right.$, $P=0.567)$.

\section{Discussion}

Only one of our four hypotheses was supported. In these annual sand dune communities, species and functional group composition do shift in response to manipulations of interaction intensity, but the shifts are independent of resource levels and remain even while total community abundance converges over time. Also, simple traits such as functional group identity and individual size do not predict competitive ability, and competitive ability is not correlated with abundance in the field.

The wide range of planting densities would have produced large differences among treatments in total community abundance in the first year, so that the potential for species interactions would have also differed greatly (Goldberg et al. 2001). However, natural regeneration was allowed in subsequent years, so that community abundance and interaction intensity were expected to converge over time. Our harvest biomass data indicate that differences among density treatments had diminished after three growing seasons (from 0.06:1:4 to 0.35: $1: 1.19$ ), but that the treatments had not completely converged to a common biomass. Convergence was most apparent between the $1 \times$ and $4 \times$ initial densities, and at low irrigation, although the irrigation $\times$ density interaction was only marginally significant. The pattern of incomplete convergence 
of community abundance over time, with greater convergence under low resource levels, is consistent with the results of a similar 2-year study in the same system (Shilo-Volin et al. 2005).

The initial intensity of species interactions did influence community structure, as predicted. Reduced interactions $(1 / 16 \times$ initial planting density) resulted in a large shift in species composition relative to natural density, while increased interaction intensity ( $4 \times$ planting density) had less of an effect (Fig. 2). While total community abundance converged over time among treatments, the density effects on composition persisted; a significant year $\times$ density interaction was found only for functional group composition in one source community for one irrigation treatment.

The persistence of initial density effects over time suggests that, for at least some species, successful growth in the first year led to reproductive success and dominance in the seed bank available for germination in subsequent years. Some seeds from the initial planting presumably failed to germinate in the first year and would have been available to germinate in later years, but actual germination seems to have been influenced by composition in the first year. Data on the age structure of seed banks are rare, and the degree to which emerging seedlings come from the previous year's seed production is unclear. Seeds may remain viable for decades (Darlington \& Steinbauer 1961). However, several studies have demonstrated exponential declines in seed viability and emergence from the seed bank with age (Roberts \& Feast 1973; Moriuchi et al. 2000; Meyer et al. 2006). While species differ in their persistence in the seed bank (Roberts \& Feast 1973), for one Sonoran Desert annual, the maximum time of survival in the seed bank was 5 years, with a mean of only 2 years (Moriuchi et al. 2000).

In addition to density effects on community composition, composition in year 1 differed from that in years 2 and 3, with an increasing proportion of grasses and legumes relative to dicots over time (Fig. 2). While some species that grew well in year 1 reappeared in subsequent years, leading to a persistent density effect, other species experienced increases or decreases unrelated to density over time. This shift may be due to differences in environment among years. Although years 1 and 3 were much more similar in precipitation than years 2 and 3 (total precipitation was 58.1, 139.8, and $51.35 \mathrm{~mm}$ in years 1,2 , and 3 , respectively), year 1 was warmer than years 2 and 3 (average growing season temperature was $15.1,13.8$, and $14.3^{\circ} \mathrm{C}$, and growing season minimum temperature was 9.1, 7.6, and $7.8^{\circ} \mathrm{C}$ in years 1,2 , and 3 , respectively). We previously showed that low temperatures limit species richness in this system (Rajaniemi et al. 2006). Alternatively, the year effect may reflect an adjustment of the community to experimental conditions in the common garden: some species with successful growth in the first year did not successfully reproduce and/or emerge in later years.

Contrary to our second hypothesis, density effects did not interact with irrigation. Plant community theory has predicted that competition is most important in high productivity environments (Grime 1973; Huston 1979; Keddy 1990) or that competition is equally important regardless of productivity (Newman 1973; Tilman 1982, 1988; Tilman \& Pacala 1993). Our earlier studies in this system did not support either prediction. Instead, competition led to faster convergence of planting densities under low irrigation with low production (Shilo-Volin et al. 2005), and competition had the strongest effects on individual growth under low irrigation (Goldberg et al. 2001). In the present experiment, irrigation treatments had significant effects on both species composition and functional group composition, but the magnitude of these effects did not depend on initial density. The lack of an interaction is more consistent with Tilman's prediction, but in our case the shift from belowground to aboveground competition predicted by Tilman is unlikely: light interception by the vegetation was uniformly low $(13.3 \% \pm 10.7 \%$ mean $\pm \mathrm{SD})$. We cannot rule out a shift from water limitation to limitation by some other soil resource.

Although species interactions did affect species composition, we were unable to make any generalizations about the traits of species that perform best under intense competition. At the individual level, grasses are better competitors than dicots in this system - their emergence and survival, but not growth, is less affected by high community densities (Goldberg et al. 2001). However, at the community level, functional group composition did not respond strongly to density (Table 2). One possible reason that individual-level responses do not scale up to the community level is that the life history stages at which grasses are consistently the superior competitors (emergence and survival) may be less important to determining relative abundance than other stages, such as growth and reproduction (Goldberg et al. 1999). Instead of strong functional group differences, competitive ability varied considerably within each functional group. Some grass species were strong competitors (e.g., high abundance of C. philistaea and Lagurus ovatus is associated with high 
planting density; Fig. 2) and others were poor competitors (e.g., Ctenopsis pectinella).

Maximum individual biomass also did not predict competitive ability even though this has been the plant trait most strongly correlated with competitive ability in a number of sets of pairwise competition experiments (Gaudet \& Keddy 1988; Goldberg \& Landa 1991; Cahill et al. 2005). Again, there was a great deal of variation within groups. Some large species, such as Reboudia pinnata and Matthiola livida, were good competitors, while other large species, such as Rumex bucephalophorus and $R$. pictus, were poor competitors. Some of this variation may result from species succeeding at different aspects of competition. A species may maintain high relative abundance under intense competition by suppressing neighbors (competitive effect), or by tolerating the presence of neighbors (competitive response; Goldberg 1990), and competitive effect and response may be uncorrelated (Goldberg \& Landa 1991; Keddy et al. 1994). Large size predicts strong competitive effect, but not response (but see Goldberg \& Landa 1991; Keddy et al. 1994; Cahill et al. 2005).

Previous studies linking traits with competitive ability have measured competitive ability as change in individual growth in response to neighbors (Gaudet \& Keddy 1988; Goldberg \& Landa 1991; Cahill et al. 2005), while we measured change in relative abundance. These studies also considered competition against a single neighbor species. In a diverse community with multispecies interactions, single simple traits may not be sufficient to predict competitive ability. A more complete screening of traits, along with use of statistical methods to summarize multiple traits, may be more successful (see Craine et al. 2001; Suding et al. 2003 for examples using multiple traits to predict abundance).

In our study, competitive ability was also unrelated to average relative abundance in the field. Community structure most likely results from a combination of competitive effects with other factors, such as dispersal limitation, precipitation, temperature extremes, and responses to disturbance and herbivory (Suding et al. 2003; Rajaniemi et al. 2006).

In these two annual plant communities, species interactions had strong effects on community structure, and these effects had a legacy that persisted for at least 2 more years, even as differences in interaction intensity among treatments diminished. In these communities, natural plant density varies three- to 100 -fold within a single year, resulting in spatial variation in the intensity of species interac- tions (Rajaniemi et al. 2006). This variation, which should have effects that last beyond a single growing season, may function to maintain diversity through a spatial storage effect (Chesson \& Warner 1981), with different species dominating different microsites depending on their recent history of plant density. Further screening of plant traits will be needed to understand which species dominate highor low-interaction intensity.

Acknowledgements. Financial support was provided by the US-Israel BiNational Science Foundation (BSF 91-00179 to DG and Linda Olsvig-Whittaker), the National Science Foundation (DEB 96-2973 to DG, RT, and Jessica Gurevitch), and the Natural Sciences and Engineering Research Council of Canada (to RT). Rachel MacKay and Mike Treberg provided statistical help. This is publication no. 647 of the Mitrani Department of Desert Ecology.

\section{References}

Aerts, R. 1999. Interspecific competition in natural plant communities: mechanisms, trade-offs and plant-soil feedbacks. Journal of Experimental Botany 50: 29-37.

Bertness, M.D. \& Callaway, R. 1994. Positive interactions in communities. Trends in Ecology \& Evolution 9: 191-193.

Cahill, J.F., Kembel, S.W. \& Gustafson, D.J. 2005. Differential genetic influences on competitive effect and response in Arabidopsis thaliana. Journal of Ecology 93: 958-967.

Chapin, F.S. 1980. The mineral nutrition of wild plants. Annual Review of Ecology and Systematics 11: 233-260.

Chase, J.M. \& Leibold, M.A. 2003. Ecological niches: linking classical and contemporary approaches. University of Chicago Press, Chicago.

Chesson, P.L. \& Warner, R.R. 1981. Environmental variability promotes coexistence in lottery competitive systems. American Naturalist 117: 923-943.

Craine, J.M. 2005. Reconciling plant strategy theories of Grime and Tilman. Journal of Ecology 93: 1041-1052.

Craine, J.M., Froehle, J., Tilman, D.G., Wedin, D.A. \& Chapin, F.S. 2001. The relationships among root and leaf traits of 76 grassland species and relative abundance along fertility and disturbance gradients. Oikos 93: 274-285.

Darlington, H.T. \& Steinbauer, G.P. 1961. The eightyyear period for Dr. Beal's seed viability experiment. American Journal of Botany 48: 321-325.

Feinbrun-Dothan, N. \& Danin, A. 1991. Analytical flora of the land of Israel. Cana, Jerusalem.

Gaudet, C.L. \& Keddy, P.A. 1988. A comparative approach to predicting competitive ability from plant traits. Nature 334: 242-243. 
Goldberg, D.E. 1990. Components of resource competition in plant communities. In: Grace, J.B. \& Tilman, D. (eds.) Perspectives on plant competition. pp. 27-49. Academic Press, San Diego.

Goldberg, D.E. 1994. Influence of competition at the community level: an experimental version of the null models approach. Ecology 75: 1503-1506.

Goldberg, D.E. \& Barton, A.M. 1992. Patterns and consequences of interspecific competition in natural communities: a review of field experiments with plants. American Naturalist 139: 771-801.

Goldberg, D.E. \& Estabrook, G.F. 1998. Separating the effects of number of individuals sampled and competition on species diversity: an experimental and analytic approach. Journal of Ecology 86: 983-988.

Goldberg, D.E. \& Landa, K. 1991. Competitive effect and response: hierarchies and correlated traits in the early stages of competition. Journal of Ecology 79: 1013-1030.

Goldberg, D.E., Turkington, R. \& Olsvig-Whittaker, L. 1995. Quantifying the community-level consequences of competition. Folia Geobotanica \& Phytotaxonomica 30: 231-242.

Goldberg, D.E., Rajaniemi, T., Gurevitch, J. \& StewartOaten, A. 1999. Empirical approaches to quantifying interaction intensity: competition and facilitation along productivity gradients. Ecology 80: 1118-1131.

Goldberg, D.E., Turkington, R., Olsvig-Whittaker, L. \& Dyer, A.R. 2001. Density dependence in an annual plant community: variation among life history stages. Ecological Monographs 71: 423-446.

Grime, J.P. 1973. Competitive exclusion in herbaceous vegetation. Nature 242: 344-347.

Grime, J.P. 1979. Plant strategies and vegetation processes. John Wiley and Sons, New York.

Howard, T.G. 2001. The relationship of total and pergram rankings in competitive effect to the natural abundance of herbaceous perennials. Journal of Ecology 89: 110-117.

Huston, M. 1979. A general hypothesis of species diversity. American Naturalist 113: 81-101.

Keddy, P.A. 1990. Competitive hierarchies and centrifugal organization in plant communities. In: Grace, J. $\&$ Tilman, D. (eds.) Perspectives on plant competition. pp. 265-290. Academic Press, San Diego.

Keddy, P.A. 2001. Competition. Kluwer Academic Publishers, Norwell, MA.

Keddy, P.A., Twolan-Strutt, L. \& Wisheu, I.C. 1994. Competitive effect and response rankings in 20 wetland plants: are they consistent across three environments? Journal of Ecology 82: 635-643.

Lenssen, J.P.M., van de Steeg, H.M. \& de Kroon, H. 2004. Does disturbance favour weak competitors? Mechanisms of changing plant abundance after flooding. Journal of Vegetation Science 15: 305-314.

McPeek, M.A. \& Peckarsky, B.L. 1998. Life histories and the strengths of species interactions: combining mortality, growth, and fecundity effects. Ecology 79: 867-879.
Meyer, S.E., Quinney, D. \& Weaver, J. 2006. A stochastic population model for Lepidium papilliferum (Brassicaceae), a rare desert ephemeral with a persistent seed bank. American Journal of Botany 93: 891-902.

Michalet, R., Brooker, R.W., Cavieres, L.A., Kikvidze, Z., Lortie, C.J., Pugnaire, F.I., Valiente-Banuet, A. \& Callaway, R.M. 2006. Do biotic interactions shape both sides of the humped-back model of species richness in plant communities? Ecology Letters 9: 767-773.

Moriuchi, K.S., Venable, D.L., Pake, C.E. \& Lange, T. 2000. Direct measurement of the seed bank age structure of a Sonoran Desert annual plant. Ecology 81: 1133-1138.

Newman, E.I. 1973. Competition and diversity in herbaceous vegetation. Nature 244: 310 .

Oksanen, L., Fretwell, S.D., Arruda, J. \& Niemelä, P. 1981. Exploitation ecosystems in gradients of primary productivity. The American Naturalist 118: 240-261.

Rajaniemi, T.K. \& Goldberg, D.E. 2000. Quantifying individual- and community-level effects of competition using experimentally determined null species pools. Journal of Vegetation Science 11: 433-442.

Rajaniemi, T.K., Allison, V.J. \& Goldberg, D.E. 2003. Root competition can cause a decline in diversity with increased productivity. Journal of Ecology 91: 407-416.

Rajaniemi, T.K., Goldberg, D.E., Turkington, R. \& Dyer, A.R. 2006. Quantitative partitioning of regional and local processes shaping regional diversity patterns. Ecology Letters 9: 121-128.

Reynolds, H.L. \& Rajaniemi, T.K. 2007. Plant interactions: competition. In: Pugnaire, F.I. \& Valladares, F. (eds.) Functional plant ecology. pp. 457-480. CRC Press, Boca Raton, FL.

Roberts, H.A. \& Feast, P.M. 1973. Emergence and longevity of seeds of annual weeds in cultivated and undisturbed soil. Journal of Applied Ecology 10: 133-143.

Shilo-Volin, H., Novoplansky, A., Goldberg, D.E. \& Turkington, R. 2005. Density regulation in annual plant communities under variable resource levels. Oikos 108: 241-252.

Suding, K.N., Goldberg, D.E. \& Hartman, K.M. 2003. Relationships among species traits: separating levels of response and identifying linkages to abundance. Ecology 84: 1-16.

Taylor, D.R., Aarssen, L.W. \& Loehle, C. 1990. On the relationship between $\mathrm{r} / \mathrm{K}$ selection and environmental carrying capacity: a new habitat template for plant life history strategies. Oikos 58: 239-250.

Tilman, D. 1982. Resource competition and community structure. Princeton University Press, Princeton, NJ.

Tilman, D. 1988. Plant strategies and the dynamics and structure of plant communities. Princeton University Press, Princeton, NJ.

Tilman, D. \& Pacala, S.W. 1993. The maintenance of species richness in plant communities. In: Ricklefs, 
R.E. \& Schluter, D. (eds.) Species diversity in ecological communities: historical and geographic perspectives. pp. 13-25. University of Chicago Press, Chicago.

Zamfir, M. \& Goldberg, D.E. 2000. The effect of initial density on interactions between bryophytes at individual and community levels. Journal of Ecology 88: 243-255.

Received 17 March 2009;

Accepted 25 March 2009.

Co-ordinating Editor: C. Canham. 